\title{
Coverage Validation Survey for Lymphatic Filariasis Treatment in Itang Special District of Gambella Regional State of Ethiopia: A Cross-Sectional Study
}

\author{
Abinet Teshome' \\ Mekuria Asnakew Asfaw (iD) ${ }^{2}$ \\ Chuchu Churko iD ${ }^{2}$ \\ Manaye Yihune iD $^{3}$ \\ Yilma Chisha ${ }^{3}$ \\ Birhanu Getachew ${ }^{4}$ \\ Nebiyu Negussu Ayele ${ }^{5}$ \\ Fikre Seife ${ }^{6}$ \\ Tamiru Shibiru $^{7}$ \\ Zerihun Zerdo ${ }^{2}$ \\ 'Arba Minch University, College of \\ Medicine and Health Sciences, \\ Department of Biomedical Science, Arba \\ Minch, Ethiopia; ${ }^{2}$ Arba Minch University, \\ College of Medicine and Health Sciences, \\ Collaborative Research and Training \\ Center for Neglected Tropical Diseases, \\ Arba Minch, Ethiopia; ${ }^{3}$ Arba Minch \\ University, College of Medicine and \\ Health Sciences, School of Public Health, \\ Arba Minch, Ethiopia; ${ }^{4}$ Ethiopian Public \\ Health Institute, Bacterial, Parasitic and \\ Zoonotic Diseases Research Directorate, \\ Addis Ababa, Ethiopia; ${ }^{5}$ Federal Ministry \\ of Health, Department of Health System \\ Research, Addis Ababa, Ethiopia; ${ }^{6}$ Federal \\ Ministry of Health, Disease Prevention \\ and Control Directorate, Addis Ababa, \\ Ethiopia; ${ }^{7}$ Arba Minch University, College \\ of Medicine and Health Sciences, School \\ of Medicine, Arba Minch, Ethiopia
}

Correspondence: Abinet Teshome Email ableteshe@yahoo.com
Background: Lymphatic filariasis (LF) is one of the most debilitating and disfiguring diseases common in Ethiopia. In order to alleviate this problem Mass drug administration (MDA) has been given once a year for the public living in endemic sites. Despite this fact there might be a difference between reported coverage and the actual coverage on the ground due to various errors, so assessing the actual coverage through coverage validation survey appears imperative. Objective: The aim of this survey was to assess the difference between the reported coverage and actual coverage of Ivermectin (IVM) and Albendazole (ALB) treatment given for Lymphatic Filariasis in Itang special district of Gambella regional state, Ethiopia. Setting: The study was conducted in Itang special district of Gambella region, the district was purposively selected for lymphatic filariasis treatment coverage survey. Eligible individuals aged 5 and above were interviewed. Data about the children were collected from parents or guardians and analyzed using STATA.

Results: The survey showed that the coverage for LF treatment was $81.5 \%$. From 825 individuals that reported that they were offered the treatment $823(99.6 \%)$ swallowed the drug. The coverage in school age children (5-14) shows significant difference with treatment coverage in individuals aged 15 and above $(\mathrm{p}<0.001)$ in the last mass drug administration campaign. The main reason for not being offered preventive chemotherapy (PC) during the mass drug administration campaigns was missing class during the MDA (37.2\%).

Conclusion: The treatment coverage is higher than the recommended coverage of $65 \%$ of the target population. The coverage in school age children (5-14) showed significant difference with treatment coverage in individuals aged 15 and above. Improving the coverage level beyond this can significantly contribute to the LF elimination goal.

Keywords: lymphatic filariasis, ivermectin, albendazole, coverage

\section{Introduction}

Lymphatic filariasis (LF) is parasitic disease transmitted by Anopheles mosquito and is endemic in several countries in Africa. About 893 million people in 49 countries live in areas where they are at risk of Lymphatic filariasis. ${ }^{1}$ The disease is a neglected tropical disease (NTD) caused by three species of filarial worm: Wuchereria bancrofti, Brugia malayi and Brugia timori and is transmitted through an infected mosquito's bite. Whilst infection can be acquired during childhood, the overt chronic manifestations of the disease may occur in later life. The main signs in the infected individual are lymphoedema of the limbs, hydrocele and recurrent acute attacks. It is estimated that 19.4 million men worldwide suffer from 
hydrocoele and almost 16.7 million individuals, mostly women, have lymphoedema of the leg. ${ }^{2}$ Lymphatic filariasis is endemic in third world countries including Africa. Approximately $30 \%$ of individuals that are at risk live in sub-Saharan Africa. ${ }^{3}$

LF is one of the most debilitating and disfiguring diseases common in Ethiopia and in this country the disease is mainly caused by Wuchereria bancrofti and it is mainly transmitted via the bite of Anopheles mosquito., ${ }^{4,5}$ 5.9 million people living in 70 endemic districts have been estimated to be at risk of LF in Ethiopia. ${ }^{6}$

Annual MDA with a combination of Ivermectin and Albendazole is recommended for the control of LF in African countries which are co-endemic for onchocerciasis. ${ }^{7}$ Successful elimination of LF based on the MDA strategy relies on maintaining a high treatment coverage to reduce the worm burden in humans and hence the onwards transmission. ${ }^{8}$ However, attaining and maintaining high treatment coverage has been a challenge in many LF control programs globally. ${ }^{9}$ Given that the required duration of MDA is based on the estimated reproductive lifespan of the adult worm, at least five rounds of MDA with a minimum coverage of $65 \%$ of the total population is considered to be adequate in order to reduce microfilariae to a level at which transmission will end without further interventions. ${ }^{10}$

Elimination of LF as a public health problem is operationally defined as reducing infection to levels at which transmission is no longer sustainable and ensuring the availability of a WHO-recommended basic package of care to manage lymphoedema and hydrocele. The following measurable elimination thresholds must be demonstrated before stopping MDA: (i) microfilaremia prevalence of less than $1 \%$ or antigenemia prevalence of less than $2 \%$ in sentinel and spot-check surveys; and (ii) incident infection below $1 \%$ or $2 \%$ measured during the transmission assessment survey. ${ }^{11}$

At the turn of the 20th century, it was estimated that 120 million people were infected with L globally and more than one billion were at risk of infection. A strategy of MDA, following the 1997 World Health Assembly resolution to eliminate LF, has led to one of the most ambitious and successful interventions against a neglected tropical disease. Under sufficient level of intervention coverage, transmission of LF can be interrupted within five years. ${ }^{12}$

According to mapping done in different districts of Ethiopia, the prevalence was found to be $3.7 \%$, but high geographical clustering and variation in prevalence (ranging from $0 \%$ to more than $50 \%$ ) was found. In the mapping the endemic districts were found in Gambella, Benishangul-Gumuz, and Southern Nations, Nationalities and Peoples' regions, Amhara and Oromia regions, with Benishangul- Gumuz having the highest number of endemic districts with $13{ }^{4}$

Treatment coverage and community compliance are important factors for successful LF elimination through the MDA strategy. It has been shown that in areas with high pre-MDA levels of infection, maintaining high drug intake during MDA is crucial in order to reach the elimination goal within a reasonable time frame. ${ }^{17}$

In 2009, the Ethiopian government initiated the implementation of the national LF elimination program integrated with the onchocerciasis control program, to undertake programs aimed at controlling and eliminating lymphatic filariasis as a public health problem in Ethiopia by $2020 .^{2}$

Integrated delivery of community-based public health services demonstrated a high absolute post-intervention coverage. Programs and governments are increasingly integrating service distribution to streamline delivery of a variety of services and reduce costs ${ }^{19}$ and the mass drug administration survey in Ethiopia has been given in integrated manner since its inception in 2013 and showed an improvement in coverage.

To achieve elimination of LF annual doses of albendazole and ivermectin and provision of minimum care to every person with associated LF chronic manifestation has been in place for individuals living in lymphatic filariasis endemic areas accompanied by morbidity management and vector control. Even though there appears to be a considerable geographical coverage change since its inception in 2009 all eligible individuals for lymphatic filariasis preventive chemotherapy did not receive the drugs in the previous consecutive mass drug administration campaigns.

Despite routine coverage reports exist in the health system of Ethiopia, these reports are often liable for errors and may not show the actual coverage of the sites. Therefore, the aim of this coverage validation survey was to evaluate the treatment coverage of PC against LF in Itang special district of Gambella Regional State in Ethiopia. This study aims to measure validated treatment coverage of IVM(Ivermectin) plus ALB(Albendazole) in the population aged 5 and above, assess coverage in SAC (school age children) disaggregated by gender, collect information on why targeted eligible individuals did not receive treatment and assess the site of treatment. The 
mass drug administration for lymphatic filariasis was conducted in November, 2018 in the study area and the coverage validation survey was conducted in April, 2019.

\section{Methods}

\section{Study Settings}

Gambella regional state of Ethiopia was selected for this study by Federal Ministry of Health (FMoH). This regional state was purposively selected based on endemicity of LF and doubt on routine reports of treatment coverage. Also, from this region, one district (Itang) was selected for the study. In Itang special district treatment for LF was given for those aged five and above, so they were the ones interviewed about the preventive chemotherapy in the last round of MDA.

\section{Study Design and Period}

A community based cross-sectional study was conducted from April 1 to 30, 2019.

\section{Sample Size and Sampling Technique}

A total of 30 segments of households were randomly selected from the district using coverage survey builder tool, which is an excel-based tool used to design a coverage validation survey. From each selected segment, at least 16 randomly selected households were included in the survey. The name of kebeles and number of households to be involved in the survey from each segment was determined before the actual data collection. In the field, data collectors visited the kebeles (the smallest administrative unit in Ethiopia) to assess the total number of households and population. Then, the data collectors divided the total households in each kebele to 50 to determine the number of segments. The division of the segments and selection of the households was done based on the WHO criteria of coverage evaluation survey field guide. ${ }^{21}$

\section{Study Population}

The study population was all individuals aged five years and above from each selected household.

\section{Data Collection}

Data were collected by health professionals using face-to face interview by smartphone through the survey CTO software. If there was no participant in the selected household or if the entire household absent and not expected to return later in the day, the survey team proceeded to the next selected household. If a child $>10$ years was absent but expected to return later in the same day, the survey team made an attempt to revisit the household.

\section{Study Variables}

- Swallowed ivermectin and albendazole (yes or no)

- Offered ivermectin and albendazole (yes or no)

- Age

- Sex

- Heard about mass drug administration

- Name of district

- School attendance

- Reasons for not being offered or not swallowing the drug

\section{Data Processing and Analysis}

Data were analyzed using STATA version 14. In this study, treatment coverage is referred as proportion of study population who swallowed the drug per total eligible population. Data were disaggregated by offering and swallowing status of ivermectin and albendazole with sex, age and school attendance. Chi-Square test $\left(X^{2}\right)$ test was used to check the difference among different groups.

\section{Data Quality Control}

Data quality was maintained through training of data collectors and supervisors on data collection tool, pre-testing tools and involvement of previous experienced data collectors and supervisors. In addition, data collection was daily checked for consistency and accuracy of data by supervisors.

\section{Ethical Considerations}

The study was conducted in accordance with the Declaration of Helsinki. This coverage validation survey is part of FMoH LF elimination program. The study was reviewed and approved by Institutional Research Ethics Review Board of College of Medicine and Health Sciences, Arba Minch University. Before collecting data, the information sheet was read for all respondents and the interview took place only when they agreed to sign the digital consent on the data collection tablet. Informed oral and written consents were received from heads of the household or caregivers before data collection started. 


\section{Results}

\section{Mass Drug Administration Coverage Against Lymphatic Filariasis}

The treatment coverage validation survey data of Lymphatic Filariasis was collected only from Itang special district in Gambella regional state. A total of 2125 individuals were eligible for interview, out of which 2082 were interviewed which gives a response rate of $98 \%$. Of the 2082 individuals, $81.5 \%$ were offered treatment while $17.8 \%$ and $0.7 \%$ were not offered the drug or unknown (cannot recall whether they took the drug or not) respectively. From those who were offered treatment against lymphatic Filariasis 99.8\% swallowed the drug offered. When reviewing the treatment coverage in males and females, the percentage of individuals that were offered the treatments among males and females were $81.7 \%$ and $81.3 \%$, respectively. A chi-square test showed no significant difference in treatment offered between males and females (p-value, 0.884) (Table 1).

The percentage of individuals who swallowed IVM \&ALB among respondents that were offered the drugs was $99.8 \%$ and $99.9 \%$ for males and females respectively (Table 2).

The treatment coverage of IVM plus Albendazole for lymphatic filariasis in Itang district was $81.7 \%$ (Table 3 ).

\section{Reasons for Not Being Offered LF MDA in Gambella Regional State}

The main reasons for not being offered IVM plus ALB were being absent from school 138 (37.2\%) and not knowing about the deworming $113(30.46 \%)$. A total of 16 individuals replied other reasons such as not being interested (1), not being around (1), change of living area (2),
Table 2 Drugs Swallowed Against LF Disaggregated by Gender, Age and School Attendance (5-14) Among Individuals 5 Years and Above in Itang Special Woreda of Gambella, Ethiopia 2019

\begin{tabular}{|c|c|c|c|c|}
\hline \multirow[t]{2}{*}{ Characteristics } & \multirow[t]{2}{*}{ Category } & \multirow[t]{2}{*}{ Frequency } & \multicolumn{2}{|c|}{$\begin{array}{l}\text { Swallowed IVM } \\
\text { Plus ALB }\end{array}$} \\
\hline & & & Yes & No \\
\hline Sex & $\begin{array}{l}\text { Male } \\
\text { Female }\end{array}$ & $\begin{array}{l}825 \\
871\end{array}$ & $\begin{array}{l}823(99.8) \\
870(99.9)\end{array}$ & $\begin{array}{l}2(0.2) \\
I(0.1)\end{array}$ \\
\hline Age cat & $\begin{array}{l}5-14 \\
\geq 15\end{array}$ & $\begin{array}{l}569 \\
1127\end{array}$ & $\begin{array}{l}567(99.7) \\
\mathrm{I} 126(99.9)\end{array}$ & $\begin{array}{l}2(0.3) \\
I(0.1)\end{array}$ \\
\hline $\begin{array}{l}\text { SAC school } \\
\text { attendance }\end{array}$ & $\begin{array}{l}\text { Yes } \\
\text { No }\end{array}$ & $\begin{array}{l}537 \\
32\end{array}$ & $\begin{array}{l}535(99.6) \\
32(100)\end{array}$ & $\begin{array}{l}2(0.4) \\
0\end{array}$ \\
\hline
\end{tabular}

fear of side effect (1), drug given only for under 40 years old (1), unable to move (1), do not attend school (1), forgot (2) and not given for adults (6) (Figure 1). The reported reasons for not swallowing the drugs for LF were fear of side effect, bad taste and no information.

\section{Discussion}

The data collected from Itang special woreda of Gambella Region shows that the treatment coverage is higher than the WHO recommended coverage of $65 \%$ of the target population. Different factors played a role for this achievement including using different treatment sites such as schools, community centers and home to home by using health development armies for those children not attending school and for nomadic communities such as the one in Gambella Regional state.

The validated coverage of $81.5 \%$ in Itang special district of Gambella regional state is lower than the reported coverage by the federal ministry of health of Ethiopia,

Table I MDA Offered Against LF and Its Association with Gender, Age and School Attendance Among Individuals 5 Years and Above in Itang Special Woreda of Gambella (Integrated Approach), Ethiopia 2019

\begin{tabular}{|c|c|c|c|c|c|c|c|}
\hline \multirow[t]{2}{*}{ Characteristics } & \multirow[t]{2}{*}{ Category } & \multirow{2}{*}{$\begin{array}{l}\text { Frequency } \\
\text { (N\%) }\end{array}$} & \multicolumn{3}{|c|}{ IVM Plus ALB Offered (LF) } & \multirow[t]{2}{*}{ Pearson Chi-Square } & \multirow[t]{2}{*}{ P-value } \\
\hline & & & $\begin{array}{l}\text { Yes } \\
\text { (N\%) }\end{array}$ & $\begin{array}{l}\text { No } \\
\text { (N\%) }\end{array}$ & $\begin{array}{l}\text { UnKnown } \\
\text { (N\%) }\end{array}$ & & \\
\hline \multirow[t]{2}{*}{ Sex } & Male & 1010 & $825(81.7)$ & $177(17.5)$ & $8(0.8)$ & \multirow[t]{2}{*}{0.25} & \multirow[t]{2}{*}{0.884} \\
\hline & Female & 1072 & $87 I(8 I .25)$ & $194(18.1)$ & $7(0.65)$ & & \\
\hline \multirow[t]{2}{*}{ Age cat } & $5-14$ & 687 & $569(82.8)$ & $106(15.4)$ & $12(1.8)$ & \multirow[t]{2}{*}{18.5} & \multirow[t]{2}{*}{$<0.001$} \\
\hline & $\geq 15$ & 1395 & $1127(80.8)$ & $265(19)$ & $3(0.2)$ & & \\
\hline \multirow{2}{*}{$\begin{array}{l}\text { SAC school } \\
\text { attendance }\end{array}$} & Yes & 616 & $537(87.2)$ & $72(11.7)$ & $7(1.1)$ & \multirow[t]{2}{*}{80.4} & \multirow[t]{2}{*}{$<0.001$} \\
\hline & No & 71 & $32(45.1)$ & $34(47.9)$ & $5(7)$ & & \\
\hline
\end{tabular}


Table 3 Treatment Coverage of IVM Plus ALB Against LF in Itang Special District

\begin{tabular}{|c|c|c|c|c|}
\hline Characteristics & Category & Interviewed & Treated with IVM Plus ALB & Treatment Coverage (\%) \\
\hline \multirow[t]{2}{*}{ Sex } & Male & 1010 & 823 & 81.5 \\
\hline & Female & 1072 & 870 & 81.2 \\
\hline \multirow[t]{2}{*}{ Age category } & $5-14$ & 687 & 567 & 82.5 \\
\hline & $\geq 15$ & 1395 & 1126 & 80.7 \\
\hline \multirow[t]{2}{*}{ SAC School attendance } & Yes & 616 & 535 & 86.9 \\
\hline & No & 71 & 32 & 45.1 \\
\hline
\end{tabular}

which is $100 \%$. This shows that there is a discrepancy between the reported coverage and the actual coverage in the mass drug administration campaigns.

Based on WHO guideline an "effective MDA round" or reaching "effective coverage" during an MDA round is defined by epidemiological coverage of at least $65 \%$ in an implementation unit ${ }^{11}$ and the current validation survey in the Itang special district was higher than the percentage set by the WHO as the coverage was $81.5 \%$ in the indicated district.

An integrated coverage validation survey in Togo showed that more than $86 \%$ of the respondents reported that they took the drugs of lymphatic filariasis which is higher than the reported coverage in this survey. ${ }^{13}$

A median reported treatment coverage in Ghana over a period of a ten years (2000-2010) reported the coverage to be $77-80 \%$ in decade ${ }^{14}$ and another coverage validation survey in Togo showed $>88 \%$ of persons in each survey conducted 1, 6 and 12 months after the MDA indicated they were offered medication during the MDA and essentially the same proportion reported swallowing all the MDA medications they were offered. ${ }^{15}$ A lymphatic filariasis treatment validation survey in Kenya which uses a strategy of community directed with health system involvement showed coverage of $88 \%{ }^{16}$

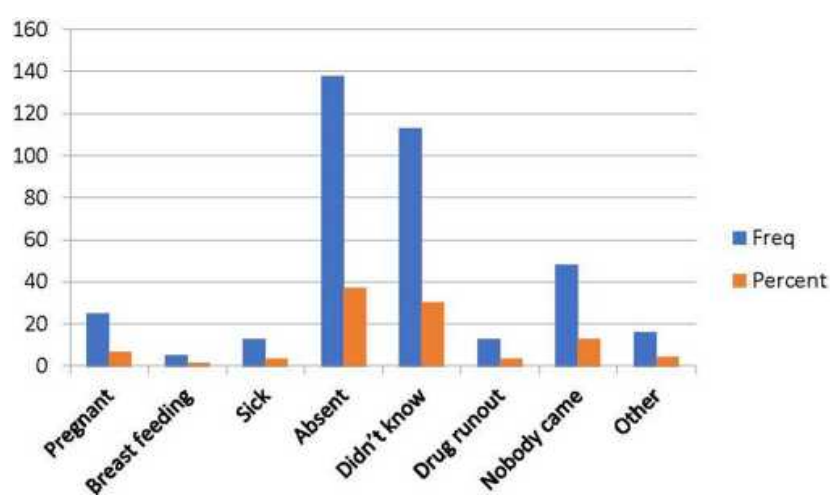

Figure I Reasons for not being offered LF MDA in Itang special district, Gambella regional state, Ethiopia, 2019, $\mathrm{N}=371$.
A study conducted in Southeast Asia showed that the number of people requiring mass drug administration fell from 1.41 billion in 2011 to 856 million in 2016.It is expected that mass administration will no longer be required when the prevalence of infection has been reduced to low levels, such as microfilariae in $<1 \%$ of the population or antigenemia in $<2 \%$ of the population. ${ }^{18}$

When comparing the coverage of Ivermectin and Albendazole for lymphatic filariasis treatment the drugs offered was significantly higher in children attending school than those not attending school $(\mathrm{p}<0.001)$ as the treatment strategy all over the country is mainly in primary schools while integrated MDAs together with STH and SCH also takes place in the community, but enrolled children have better information about the MDA and have high probability of taking the drugs during the mass drug administrations as non-enrolled children are highly likely for not being around the drug distribution sites during MDA dates. Conducting the mass drug administration in the community and house to house by using health development armies and health extension workers can be helpful in addressing students not attending school.

The coverage in school age children (5-14) shows significant difference when compared to treatment coverage in individuals aged 15 and above $(p<0.001)$ in the last mass drug administration campaign and this fact can be explained by the fact that most of the respondents were school age children and that there was a wrong assumption that the treatment is not given for adults while the treatment strategy includes all individuals aged 5 and above.

The main reason given for not taking the drugs was not being around during the campaign (37.2\%) and a similar study in Tanzania showed the same reason for not taking the preventive chemotherapy. ${ }^{7}$ The same study showed the coverage of lymphatic filariasis treatment to be $51.6 \%$ and $57.4 \%$ for two separate coverage validation survey conducted in 2011 and 2015 G.C which is considerably lower 
than our finding. Another study in Nigeria showed that among the very few that refused treatment, most did so because of fear or worry rather than personal experience of adverse events. ${ }^{20}$

The study has its own limitations as it was conducted in a single region and does not reflect the status of the whole country and there might have been a recall bias as the mass drug administration was conducted months before the coverage validation survey leading to the respondents not responding accurately to the questions.

\section{Conclusion}

Even though only a single district in Gambella regional state was included in this validation survey Ethiopia has achieved a remarkable progress to eliminate Lymphatic filariasis as witnessed by its consistent high coverage of the target population which is greater than the minimum percentage set by WHO. Geographically remote areas are also well covered by the drug distribution campaigns and using more than one hub for preventive chemotherapy proved effective as teachers, HEWs and HDAs play a significant role in seeing through the drug distributions.

There still appears to be a room for improvement as the coverage can reach $100 \%$ by improving the community sensitization and mobilization activities, providing a better training for the participants and better management of side effects because the community may resist the treatment if there are many individuals suffering from side effects.

\section{Availability of Supporting Data}

The supporting data submitted with this manuscript is not available to be used for other purposes.

\section{Consent for Publication}

Consent for publication of this article was gained from FMOH and collaborative research and training center for neglected tropical diseases (CRTC-NTDs).

\section{Acknowledgments}

We would like to acknowledge Ethiopian federal ministry of health, evidence action and Schistosomiasis control initiative for their technical and financial support to undertake this coverage validation survey. Our gratitude also goes to NTD focal person in the districts involved in the study for providing information about the kebeles and the mass drug administration, those guiders directing the households in each segment of the study sites, individual participants involved in the study and staff in college of medicine and health sciences of Arba Minch University involved in the data collection process.

\section{Author Contributions}

All authors made substantial contributions to conception and design, acquisition of data, or analysis and interpretation of data; took part in drafting the article or revising it critically for important intellectual content; agreed to submit to the current journal; gave final approval of the version to be published; and agree to be accountable for all aspects of the work.

\section{Funding}

The fund for data collection including costs for vehicle rent, allowance for data collectors and other contingencies were covered by FMOH.

\section{Disclosure}

The authors declare that they have no competing interests.

\section{References}

1. Collyer BS, Irvine MA, Hollingsworth TD, Bradley M, Anderson RM. Defining a prevalence level to describe the elimination of Lymphatic Filariasis (LF) transmission and designing monitoring \& evaluating (M\&E) programmes post the cessation of mass drug administration (MDA). PLoS Negl Trop Dis. 2020;14(10): e0008644. doi:10.1371/journal.pntd.0008644

2. Belete Mengistu KD, Kebede F, Martindale S, et al. The national program to eliminate lymphatic filariasis from Ethiopia. Ethiop Med J. 2017;55(Suppl 1):45-54.

3. Nutman TB, Kazura JW. Tropical Infectious Diseases. 3rd ed. 2011.

4. Deribe K, Meribo K, Gebre T, et al. The burden of neglected tropical diseases in Ethiopia, and opportunities for integrated control and elimination. Parasit Vectors. 2012;5:240. doi:10.1186/1756-3305$5-240$

5. Shiferaw W, Kebede T, Graves PM, et al. Lymphatic filariasis in western Ethiopia with special emphasis on prevalence of Wuchereria bancrofti antigenaemia in and around onchocerciasis endemic areas. Trans R Soc Trop Med Hyg. 2012;106(2):117-127. doi:10.1016/j. trstmh.2011.10.006

6. Federal Democratic Republic of Ethiopia Ministry of Health. Second edition of national neglected tropical diseases master plan 2015/162019/20 (2008-2012 EFY) Addis Ababa, Ethiopia. 2016.

7. Simonsen PE, Pedersen EM, Rwegoshora RT, et al. Lymphatic filariasis control in Tanzania: effect of repeated mass drug administration with ivermectin and albendazole on infection and transmission. PLoS Negl Trop Dis. 2010;4(6):e696. doi:10.1371/journal.pntd.0000696

8. Michael E, Malecela-Lazaro MN, Simonsen PE, et al. Mathematical modelling and the control of lymphatic filariasis. Lancet Infect Dis. 2004;4:223-234. doi:10.1016/S1473-3099(04)00973-9

9. Simonsen PE, Derua YA, Magesa SM, et al. Lymphatic filariasis control in Tanga Region, Tanzania: status after eight rounds of mass drug administration. Parasit Vectors. 2014;7:507. doi:10.1186/ s13071-014-0507-5

10. Bockarie MJ, Tisch DJ, Katsens W, et al. Mass treatment to eliminate filariasis in Papua New Guinea. N Engl J Med. 2002;347:1841-1848. doi:10.1056/NEJMoa021309 
11. Guideline: alternative mass drug administration regimens to eliminate lymphatic filariasis Licence: CC BY-NC-SA 3.0 IGO. Geneva: World Health Organization; 2017.

12. Garchitorena A, Raza-Fanomezanjanahary M, Mioramalala SA, et al. Toward elimination of lymphatic filariasis in southeastern Madagascar: successes and challenges for interrupting transmission. PLoS Negl Trop Dis. 2018;12(9):e0006780. doi:10.1371/journal.pntd.0006780

13. Dorkenoo MA, Bronzan R, Yehadji D, et al. Surveillance for lymphatic filariasis after stopping mass drug administration in endemic districts of Togo, 2010-2015. Parasit Vectors. 2018;11(1):244. doi:10.1186/s13071-018-2843-3

14. Biritwum NK, Frempong KK, Verver S, et al. Progress towards lymphatic filariasis elimination in Ghana from 2000-2016: analysis of microfilaria prevalence data from 430 communities. PLoS Negl Trop Dis. 2019;13(8):e0007115. doi:10.1371/journal.pntd.0007115

15. Budge PJ, Sognikin E, Akosa A, Mathieu EM, Deming M. Accuracy of coverage survey recall following an integrated mass drug administration for lymphatic filariasis, schistosomiasis, and soil-transmitted helminthiasis. PLoS Negl Trop Dis. 2016;10(1):e0004358. doi:10.1371/journal.pntd.0004358

16. Wamae N, Njenga SM, Kisingu WM, et al. Community-directed treatment of lymphatic filariasis in Kenya and its role in the national programs for elimination of lymphatic filariasis. Afr J Health Sci. 2006;13(1-2):69-79. doi:10.4314/ajhs.v13i1.30819
17. Jones C, Ngasalla B, Derua YA, et al. Lymphatic filariasis elimination efforts in Rufiji, southeastern Tanzania: decline in circulating filarial antigen prevalence in young school children after twelve rounds of mass drug administration and utilization of long-lasting insecticide-treated nets. Int $J$ Infect Dis. 2017;61:38-43. doi:10.1016/j.ijid.2017.05.009

18. Specht S, Suma TK, Pedrique B, Hoerauf A. Elimination of lymphatic filariasis in South East Asia. BMJ. 2019;364:198. doi:10.1136/ bmj.k5198

19. Deardorff KV, Rubin Means A, A'sbjo“rnsdo'ttir KH, Walson J. Strategies to improve treatment coverage in community-based public health programs: a systematic review of the literature. PLoS Negl Trop Dis. 2018;12(2):1-20. doi:10.1371/journal.pntd.0006211

20. Griswold E, Eigege A, Ityonzughul C, et al. Evaluation of treatment coverage and enhanced mass drug administration for onchocerciasis and lymphatic filariasis in five local government areas treating twice per year in Edo state, Nigeria. Am J Trop Med Hyg. 2018;99 (2):396-403. doi:10.4269/ajtmh.17-1004

21. World health organization. Coverage surveys for preventive chemotherapy: guidelines for implementation. 2016.
Infection and Drug Resistance

\section{Publish your work in this journal}

Infection and Drug Resistance is an international, peer-reviewed openaccess journal that focuses on the optimal treatment of infection (bacterial, fungal and viral) and the development and institution of preventive strategies to minimize the development and spread of resistance. The journal is specifically concerned with the epidemiology of
Dovepress

antibiotic resistance and the mechanisms of resistance development and diffusion in both hospitals and the community. The manuscript management system is completely online and includes a very quick and fair peerreview system, which is all easy to use. Visit http://www.dovepress.com/ testimonials.php to read real quotes from published authors. 